Org Lett. 2016 August 19; 18(16): 4148-4150. doi:10.1021/acs.orglett.6b02154.

\title{
Manganese-Catalyzed Carboacylations of Alkenes with Alkyl lodides
}

\author{
Caitlin M. McMahon, Matthew S. Renn, and Erik J. Alexanian ${ }^{*}$ \\ Department of Chemistry, The University of North Carolina at Chapel Hill, Chapel Hill, NC 27599, \\ United States
}

\begin{abstract}
A manganese-catalyzed carboacylation of alkenes with alkyl iodides and carbon monoxide is described. This carbonylative difunctionalization uses both primary and secondary alkyl iodides in reactions with a diverse array of cyclic and acyclic substrates. Examples of successful applications to the synthesis of 5-, 6-, and 7-membered rings are provided. The inexpensive, first-row catalytic system and mild reaction conditions are expected to facilitate applications in complex synthesis.
\end{abstract}

\section{Graphical abstract}

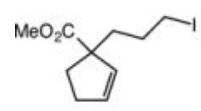
unactivated
alkyl iodides alkyl iodides

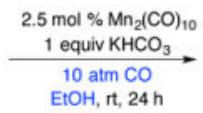

EtOH, rt, 24 h

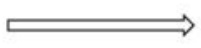

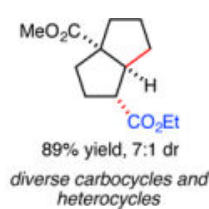

heterocycles

Catalytic reactions of unactivated alkyl halides have led to a diverse set of valuable $\mathrm{C}-\mathrm{C}$ bond-forming reactions in chemical synthesis. ${ }^{1}$ This class of transformations includes alkylMizoroki-Heck-type reactions, constituting fundamental cross-couplings of unactivated alkyl halides with alkenes. ${ }^{2}$ In prior studies, we developed a carbonylative variant of this reaction that yields cyclic enones from alkyl iodides and pendant alkenes (Figure 1). ${ }^{3} \mathrm{We}$ became interested in pursuing an alternative process involving alkene difunctionalization (carboacylation). ${ }^{4}$ Prior to our studies there was limited precedent for this class of alkene difunctionalization; a photochemical palladium-catalyzed carboacylation has been reported, but requires excess alkyl iodide (1.5 equiv) and was limited to ketone synthesis using alkylboranes. 5

We hypothesized that simple manganese catalysts [e.g., $\mathrm{Mn}_{2}(\mathrm{CO})_{10}$ ] could facilitate the desired alkene carboacylation. These complexes have shown promise in both the activation and carbonylation of unactivated alkyl halides-particularly using intense irradiation or electrolysis. ${ }^{6}$ Previous studies involving manganese-catalyzed radical cyclizations required activated a-halocarbonyls as substrates, however. ${ }^{7}$ The use of an inexpensive, first-row metal instead of precious palladium catalysts commonly used in carbonylative processes of

*Corresponding Author: eja@email.unc.edu.

Supporting Information. Experimental procedures and spectral data for all new compounds. This material is available free of charge via the Internet at http://pubs.acs.org. 
organohalides $^{8}$ would be an attractive feature of the carboacylation. Herein, we report the successful development of such a manganese-catalyzed alkene carboacylation widely applicable to carbocycle and heterocycle synthesis.

We began by studying the catalytic carboacylation of primary iodide $\mathbf{1}$ (Table 1). Inexpensive, commercially available manganese $(0)$ carbonyl successfully catalyzed the carboacylation of 1, delivering the substituted cyclopentyl ester 2 in good yield (84\%, entry $1)$ in $\mathrm{EtOH}$ as solvent. Bromopentacarbonylmanganese $(\mathrm{I})$ and cobalt $(0)$ carbonyl were both ineffective as catalysts (entries 2-3), as was $\mathrm{Pd}\left(\mathrm{PPh}_{3}\right)_{4}$, which we have previously used in a number of catalytic $\mathrm{C}-\mathrm{C}$ bond-forming reactions involving alkyl iodides (entry 4$){ }^{2 e, 3 a, 9}$ Amine bases could be used in the reaction, although yields were slightly diminished (entry 5). Reactions performed at various levels of $\mathrm{CO}$ pressure indicated that while reactions using a balloon of $\mathrm{CO}(1 \mathrm{~atm})$ were unsuccessful, high pressures were not required (entries 6-7). We chose $10 \mathrm{~atm}$ of $\mathrm{CO}$ as our standard condition owing to the convenience of using a pressurized glass tube. Interestingly, running the reaction in complete darkness shut down the catalytic process (entry 8), suggesting that ambient light plays a role in the catalytic reaction. ${ }^{10}$ Control experiments in the absence of manganese provided no product (entry 9).

With a viable catalytic system in hand, we investigated the scope of the carboacylation across a diverse range of substrates (Table 2). Reactions involving both primary and secondary iodides were successful (entries 1-2). Notably, the carboacylation is not limited to alcohol nucleophiles; diethylamine and $N$-methylaniline both afforded amide products in good yields (entries 3-4). Reactions using a variety of alkenes demonstrated the notable scope of the carboacylation (entries 5-8). Reactions involving 1,1-disubstituted and 1,1,2trisubstituted alkenes formed tetrahydrofuran and pyrrolidine derivatives containing quaternary stereocenters in good yield (entries 5-6). Importantly, the reaction is not limited to five-membered ring synthesis; acetal substrate $\mathbf{1 1}$ undergoes a 6-exo cyclization to deliver tetrahydropyran 12 (entry 7). Moreover, the carboacylation of silyloxy iodide 13 proceeded in 7-endo fashion to produce cyclic silyl ether $\mathbf{1 4}$ in good yield (78\%, entry 8 ). The regioselectivity of this ring closure is consistent with lower energy endo transition states in radical cyclizations of halomethylsilyl substrates with terminal alkenes. ${ }^{11}$ We have also demonstrated the potential for cascade carboacylation with triene substrate 15 (entry 9). The reaction of 15 proceeds via two sequential 5-exo cyclizations to deliver bicyclic product $\mathbf{1 6}$ in moderate yield (63\%).

Our studies continued with the carboacylations of five-and six-membered cycloalkenyl substrates (Table 3). These reactions allowed the construction of bicyclic compounds in efficient fashion, often with good levels of diastereoselectivity. The carboacylation of carvone-derived substrate 23 proceeded with lower diastereoselectivity, with preference for carbonylation on the opposite face from the methyl group.

A plausible catalytic cycle for the carboacylation is depicted in Scheme 1. Homolysis of the $\mathrm{Mn}-\mathrm{Mn}$ bond of manganese carbonyl generates the ${ }^{\bullet} \mathrm{Mn}(\mathrm{CO})_{5}$ radical and initiates the catalytic pathway. ${ }^{10}$ Iodine atom abstraction from the substrate (1) generates a carboncentered radical (25), which undergoes an alkene addition to produce radical 26. At this stage, radical 26 can either undergo carbonylation to provide acyl manganese $28,{ }^{6}$ or 
complete an iodine atom-transfer cyclization to deliver alkyl iodide $27 .{ }^{7}$ We have observed iodine atom-transfer intermediates in a number of our cyclizations; a representative example is shown in eq 1. Stopping the carboacylation of substrate 1 at partial conversion produces a mixture of both carboacylation product 2 and iodine atom-transfer cyclization product 27 in $19 \%$ and $18 \%$ yields, respectively $\left({ }^{1} \mathrm{H}\right.$ NMR analysis). In a separate experiment, iodide 27 underwent efficient carbonylation under the carboacylation conditions to deliver ester 2 in $81 \%$ yield (eq 2). These experiments are consistent with iodine atom-transfer cyclization playing a role in these catalytic transformations, the degree of which is likely dictated by the particular substrate and the energetics of the iodine atom transfer step involved. Ultimately, once acylmanganese 28 is formed, nucleophilic substitution delivers the carboacylation product 2 and regenerates the active catalyst.

In conclusion, we have developed a manganese-catalyzed carboacylation of alkenes using unactivated alkyl iodides and moderate pressures of $\mathrm{CO}$. This reaction exhibits broad scope in carbocycle and heterocycle synthesis, with the potential for good levels of diastereocontrol in the carboacylation process. The common molecular functionality and mild reaction conditions of this alkene difunctionalization are expected to facilitate future applications in complex molecule synthesis.

\section{Supplementary Material}

Refer to Web version on PubMed Central for supplementary material.

\section{Acknowledgments}

This work was supported by Award No. R01 GM107204 from the National Institute of General Medical Sciences.

\section{References}

1. (a) Gu J, Wang X, Xue W, Gong H. Org Chem Front. 2015; 2:1411.(b) Iwasaki, T., Kambe, N. Comprehensive Organic Synthesis II. Knochel, P., Molander, GA., editors. Vol. 3. Elsevier; Amsterdam: 2014. p. 337-391.(c) 1867 Hu X. Chem Sci. 2011; 2(c) Kambe N, Iwasaki T, Terao J. Chem Soc Rev. 2011; 40:4937. [PubMed: 21785791] (d) Rudolph A, Lautens M. Angew Chem Int Ed. 2009; 48:2656.(e) Frisch AC, Beller M. Angew Chem Int Ed. 2005; 44:674.

2. (a) Lebedev SA, Lopatina VS, Petrov ES, Beletskaya IPJ. Organomet Chem. 1988; 344:253.(b) Terao J, Watabe H, Miyamoto M, Kambe N. Bull Chem Soc Jpn. 2003; 76:2209.(c) Affo W, Ohmiya H, Fujioka T, Ikeda Y, Nakamura T, Yorimitsu H, Oshima K, Imamura Y, Mizuta T, Miyoshi K. J Am Chem Soc. 2006; 128:8068. [PubMed: 16771523] (d) Firmansjah L, Fu GCJ. Am Chem Soc. 2007; 129:11340.(e) Bloome KS, McMahen RL, Alexanian EJ. J Am Chem Soc. 2011; 133:20146. [PubMed: 22098504] (f) Weiss ME, Kreis LM, Lauber A, Carreira EM. Angew Chem Int Ed. 2011; 50:11125.(g) Millán A, Álvarez de Cienfuegos L, Miguel D, Campaña AG, Cuerva JM. Org Lett. 2012; 14:5984. [PubMed: 23148520] (h) McMahon CM, Alexanian EJ. Angew Chem Int Ed. 2014; 53:5974.(i) Zou Y, Zhou J. Chem Commun. 2014; 50:3725.(j) Yang F, Fu SY, Chu W, Li C, Tong DG. RSC Adv. 2014; 4:45838.(k) Ilves L, Matsubara T, Ichikawa S, Asako S, Nakamura EJ. Am Chem Soc. 2014; 36:13126.(1) Parasaram M, Iaroshenko VO, Gevorgyan V. J Am Chem Soc. 2014; 136:17926. [PubMed: 25494921] (m) Fu SY, Li YZ, Chu W, Li C, Tong DG. Catal Sci Technol. 2015; 5:1638.(n) Liu W, Lu L, Zhengwang C, Li C. Org Biomol Chem. 2015; 13:6170. [PubMed: 25971331]

3. (a) Bloome KS, Alexanian EJ. J Am Chem Soc. 2010; 132:12823. [PubMed: 20804186] For a recent intermolecular variant using styrenes, see:(b) Sumino S, Ui T, Hamada Y, Fukuyama T, Ryu I. Org Lett. 2015; 17:4952. [PubMed: 26440909] 
4. For a photochemical palladium-catalyzed carboacylation using activated alkyl halides and high CO pressure (45 atm), see:(a) Fusano A, Sumino S, Fukuyama T, Ryu I. Org Lett. 2011; 13:2114.

[PubMed: 21438521] For aryl carboacylations see:(b) Seashore-Ludlow B, Danielsson J, Somfai P. Adv Synth Catal. 2012; 354:205.(c) Liu C, Widenhoefer RA. J Am Chem Soc. 2004; 126:10250. [PubMed: 15315430]

5. Ishiyama T, Murata M, Suzuki A, Miyaura N. J Chem Soc, Chem Commun. 1995:295.

6. (a) Fukuyama T, Nishitani S, Inouye T, Morimoto K, Ryu I. Org Lett. 2006; 8:1383. [PubMed: 16562897] (b) Kondo T, Tsuji Y, Watanabe Y. Tetrahedron Lett. 1988; 29:3833.(c) Kondo T, Sone Y, Tsuji Y, Watanabe Y. J Organomet Chem. 1994; 473:163.

7. (a) Gilbert BC, Kalz W, Lindsay CL, McGrail PT, Parsons AF, Whittaker DTE. Tetrahedron Lett. 1999; 40:6095.(b) Gilbert BC, Kalz W, Lindsay CI, McGrail PT, Parsons AF, Whittaker DTE. J Chem Soc, Perkin Trans 1. 2000:1187.

8. (a) Wu L, Fang X, Liu Q, Jackstell R, Beller M, Wu XF. ACS Catal. 2014; 4:2977.(b) Brennführer A, Neumann H, Beller M. Angew Chem Int Ed. 2009; 48:4114.

9. Venning ARO, Bohan PT, Alexanian EJ. J Am Chem Soc. 2015; 137:3731. [PubMed: 25746442]

10. (a) Hudson A, Lappert MF, Nicholson BK. J Chem Soc, Dalton Trans. 1977:551.(b) Meyer TJ, Caspar JV. Chem Rev. 1985; 85:187.

11. (a) Koreeda M, Hamann LG. J Am Chem Soc. 1990; 112:8175.(b) Parasram M, Iaroshenko VO, Gevorgyan V. J Am Chem Soc. 2014; 136:17926. [PubMed: 25494921] 
- Prior work: Pd-catalyzed carbonylative Mizoroki-Heck reaction

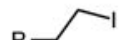

$10 \mathrm{~mol} \% \mathrm{Pd}\left(\mathrm{PPh}_{3}\right)_{4}$

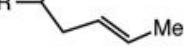

2 equiv $\mathbb{P r}_{2} \mathrm{EtN}$

$50 \mathrm{~atm} \mathrm{CO}$

$\mathrm{R}=4-(\mathrm{MeO}) \mathrm{C}_{6} \mathrm{H}_{4}$

$\mathrm{PhMe}, 130^{\circ} \mathrm{C}$

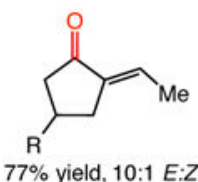

- Pd-catalyzed carboacylation: Miyaura (1995)

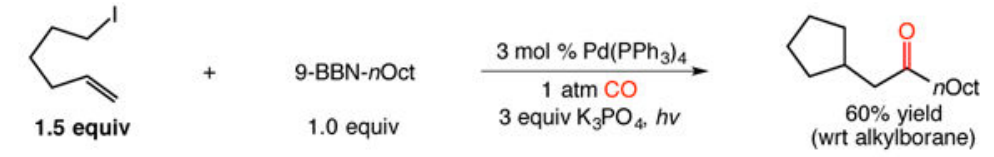

This work: Mn-catalyzed carboacylation

Figure 1.

Metal-catalyzed, carbonylative alkene additions of alkyl iodides. 


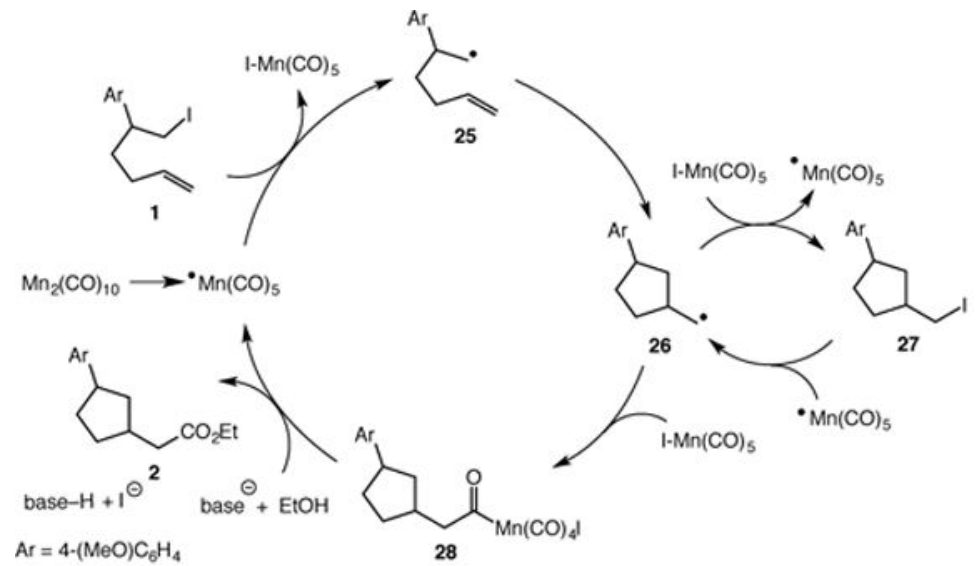

Reaction Stopped at Partial Conversion:

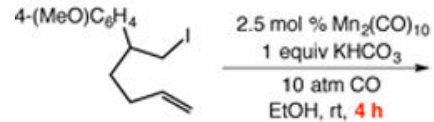

1

Carbonylation of lodine Atom-Transfer Product: 4-( $(\mathrm{MeO}) \mathrm{C}_{6} \mathrm{H}_{4}$
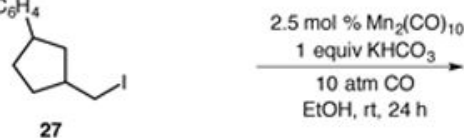

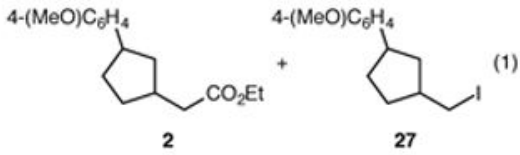

$19 \%$ yield

$18 \%$ yield

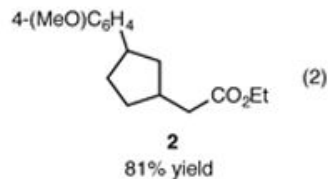

Scheme 1.

Plausible Catalytic Cycle 


\section{Table 1}

Influence of reaction conditions on the Mn-catalyzed carboacylation.

\begin{tabular}{|c|c|c|}
\hline 4-( $\left(\mathrm{MeO}_{6} \mathrm{C}_{4}\right.$ & $\begin{array}{c}2.5 \mathrm{~mol} \% \mathrm{Mn}_{2}(\mathrm{CO})_{10} \\
\underset{1 \text { equiv } \mathrm{KHCO}_{3}}{10 \mathrm{~atm} \mathrm{CO}} \\
\underset{\mathrm{EtOH}}{\mathrm{Crt}}, 24 \mathrm{~h}\end{array}$ & 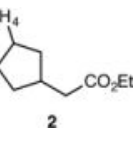 \\
\hline entry & variation from standard conditions above & yield $(\%)^{a}$ \\
\hline 1 & none & 84 \\
\hline 2 & $5 \mathrm{~mol} \% \mathrm{Mn}(\mathrm{CO})_{5} \mathrm{Br}$ instead of $\mathrm{Mn}_{2}(\mathrm{CO})_{10}$ & 14 \\
\hline 3 & $2.5 \mathrm{~mol} \% \mathrm{Co}_{2}(\mathrm{CO})_{8}$ instead of $\mathrm{Mn}_{2}(\mathrm{CO})_{10}$ & 0 \\
\hline 4 & $5 \mathrm{~mol} \% \mathrm{Pd}\left(\mathrm{PPh}_{3}\right)_{4}$ instead of $\mathrm{Mn}_{2}(\mathrm{CO})_{10}$ & 0 \\
\hline 5 & 1 equiv $\operatorname{Pr}_{2} \mathrm{EtN}$ instead of 1 equiv $\mathrm{KHCO}_{3}$ & 76 \\
\hline 6 & $1 \mathrm{~atm} \mathrm{CO}$ instead of $10 \mathrm{~atm} \mathrm{CO}$ & 0 \\
\hline 7 & $5 \mathrm{~atm} \mathrm{CO}$ instead of $10 \mathrm{~atm} \mathrm{CO}$ & 76 \\
\hline 8 & no ambient light & 0 \\
\hline 9 & no $\mathrm{Mn}_{2}(\mathrm{CO})_{10}$ & 0 \\
\hline
\end{tabular}

Reactions were performed with [substrate] $0=0.13 \mathrm{M}$.

${ }^{a}$ Yields determined by ${ }^{1} \mathrm{H}$ NMR spectroscopy of crude reaction mixture using an internal standard. 
Table 2

Manganese-Catalyzed Carboacylations of Acyclic Alkenes.

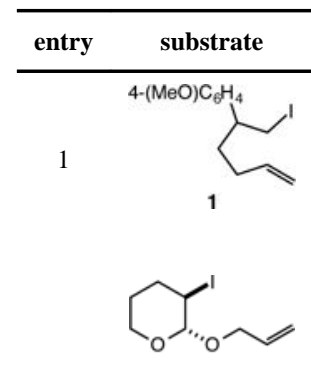

3

2

3

4

5

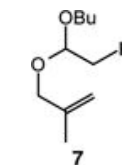

6

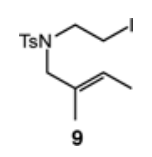

7<smiles>C/C=C/CCOC(CI)OCC</smiles>

11

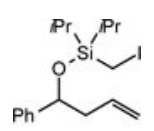

13

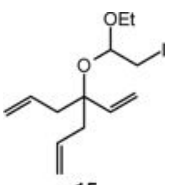

15

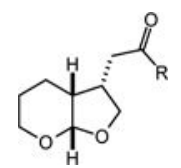

$\operatorname{yield}(\%)^{a}$

4-(MeO) $\mathrm{C}_{6} \mathrm{H}_{4}$

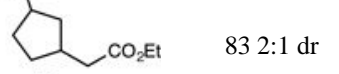$$
\text { 4: } \mathrm{R}=\mathrm{OEt} \quad 7710: 1 \mathrm{dr}
$$$$
\text { 5: } \mathrm{R}=\mathrm{NEt}_{2} \quad{ }_{67}{ }^{b} 8: 1 \mathrm{dr}
$$$$
\text { 6: } \mathrm{R}=\mathrm{NMePh} \quad 73^{b} 10: 1 \mathrm{dr}
$$$$
\mathrm{EtO}_{2} \mathrm{C} \backslash \ldots{ }_{\mathrm{Me}}^{\mathrm{O}}>\cdots \mathrm{OBu}
$$

8
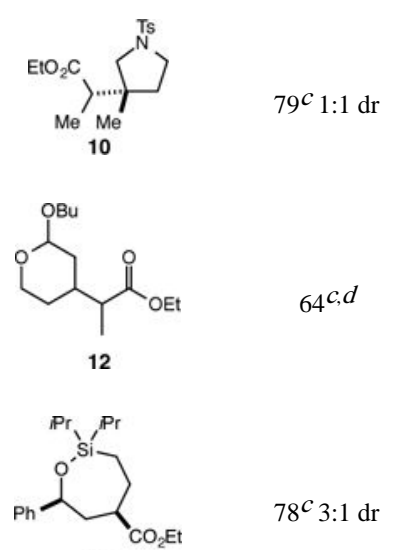

14

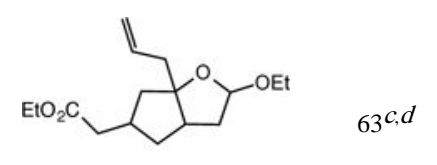

16

See Table 1 for conditions.

Isolated yields.

$b_{2}$ equiv amine and $\mathrm{KHCO}_{3}$ used.

$c_{5 \mathrm{~mol} \% \mathrm{Mn} 2(\mathrm{CO}) 10 \text { used. }}$

${ }^{d}$ Mixtures of diastereomers produced (see Supporting Information for more details).

Org Lett. Author manuscript; available in PMC 2017 August 19. 
Table 3

Manganese-Catalyzed Carboacylations of Cycloalkenyl Substrates.

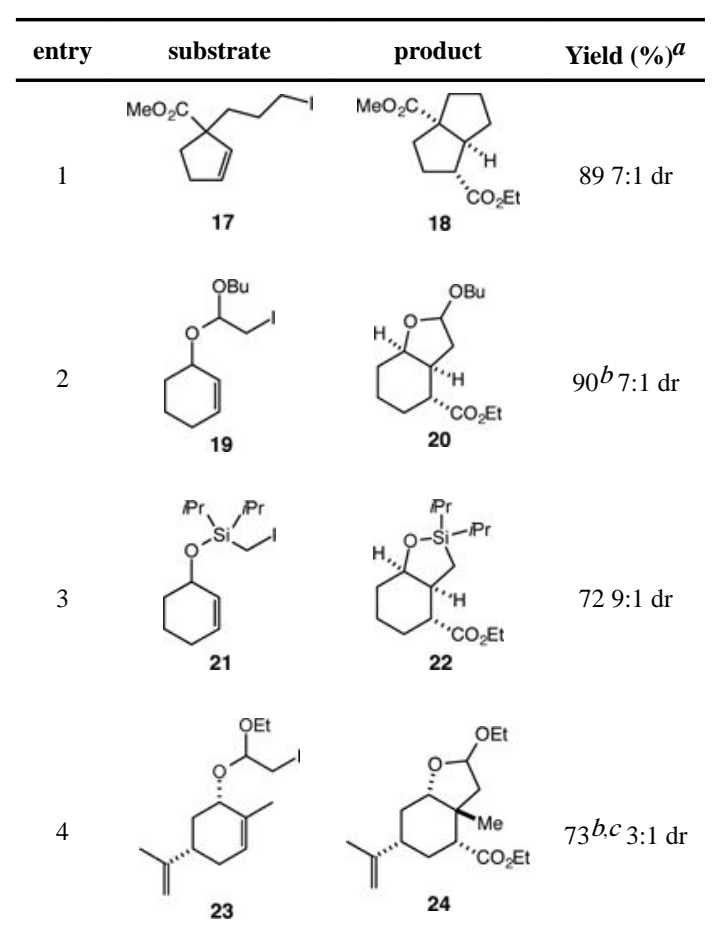

See Table 1 for conditions.

asolated yields.

$b_{\text {Diastereomeric ratio based on cyclization (see Supporting Information for more details). }}$

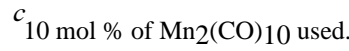

